\title{
Development of Tractor and Agricultural Equipment Simulation System
}

\author{
${ }^{1}$ Iurii A. Kotsar, ${ }^{\square} 2$ Dmitrii A. Rybalkin, ${ }^{3}$ Oleg V. Kabanov, ${ }^{4}$ Roman D. Goncharov, ${ }^{5}$ Aleksandr P. \\ Lonkin \\ 1,2,3,4 Department of Technosphere Safety and Transport and Technological Machines, FSBEI HE Saratov State \\ Agrarian University, Saratov. \\ yurii.kocar@mail.ru \\ rybalcin2903dm@mail.ru \\ oleg111974@yandex.ru \\ professor6666@gmail.com \\ ${ }^{5}$ FSBEI HE Saratov State Agrarian University, Saratov. \\ lonkin.sascha@yandex.ru
}

Received: 21st August 2020, Accepted: 14th September 2020, Published: 31st October 2020

\begin{abstract}
The article discusses an approach to the creation of a training simulator developed at Saratov State Agrarian University on the basis of modern technical and software solutions. The advantage of the proposed design of a training simulator for controlling motor and tractor equipment and agricultural units is the availability of a VR simulator for mastering the necessary skills when performing maintenance in a virtual space. The developed simulator will make it possible to increase the efficiency of the training process for tractor drivers in vocational training centers and other educational institutions with the acquisition of skills in driving tractor equipment, incl. using agricultural hinged and trailed units.
\end{abstract}

\section{Keywords}

Training Simulator, VR Technology, Operation Skills, Simulation of Operating Modes.

\section{Introduction}

The information and patent search revealed MTZ-1221 integrated multifunctional tractor simulator, containing a standard tractor cabin assembly, installed on a dynamic platform consisting of a fixed and movable base connected by six pneumatic cylinders with hinges, a panoramic screen with a viewing angle of $180^{\circ}$, rear-view mirror monitors, instructor's workplace, and motor-drives $[1,2]$.

The disadvantage of the known design $[2,3,5]$ is the insufficient panoramic view of the trainee in the cabin, and as a consequence, the lack of an overview of the soil cultivation process with agricultural units.

\section{Materials \& Methods}

Based on the foregoing, in the settings of Saratov State Agrarian University, a tractor and agricultural equipment simulation system was developed $[3,4,5,6]$.

The simulator is a modern hardware and software complex designed to teach how to drive an MTZ tractor, including in agricultural work, as well as to improve or correct the existing driving skills of tractor drivers with different levels of training.

The training simulator will be useful for training special equipment drivers in training centers, as well as for primary or secondary vocational education related to the training of tractor drivers, incl. for the agro-industrial complex.

A tractor and agricultural equipment simulation system (Fig. 1), consisting of a tractor cabin assembly 1 , mounted on a six-stage dynamic platform, consisting of a fixed 2 and a movable base 3 , interconnected by pneumatic cylinders 4 with hinges 5; instead of glasses the tractor cabin is equipped around the perimeter with the monitors $6,7,8,9,10,11,12,13$; the instructor's workplace 14 , an independent compressed air supply system 15 . Between the movable 3 and fixed 2 bases of the six-stage dynamic platform, connected by four pneumatic cylinders 4 with hinges 5, a base 16 is installed, in the center of which a hinge 17 and a guide sleeve 18 are located for communication with the movable base 3 . 


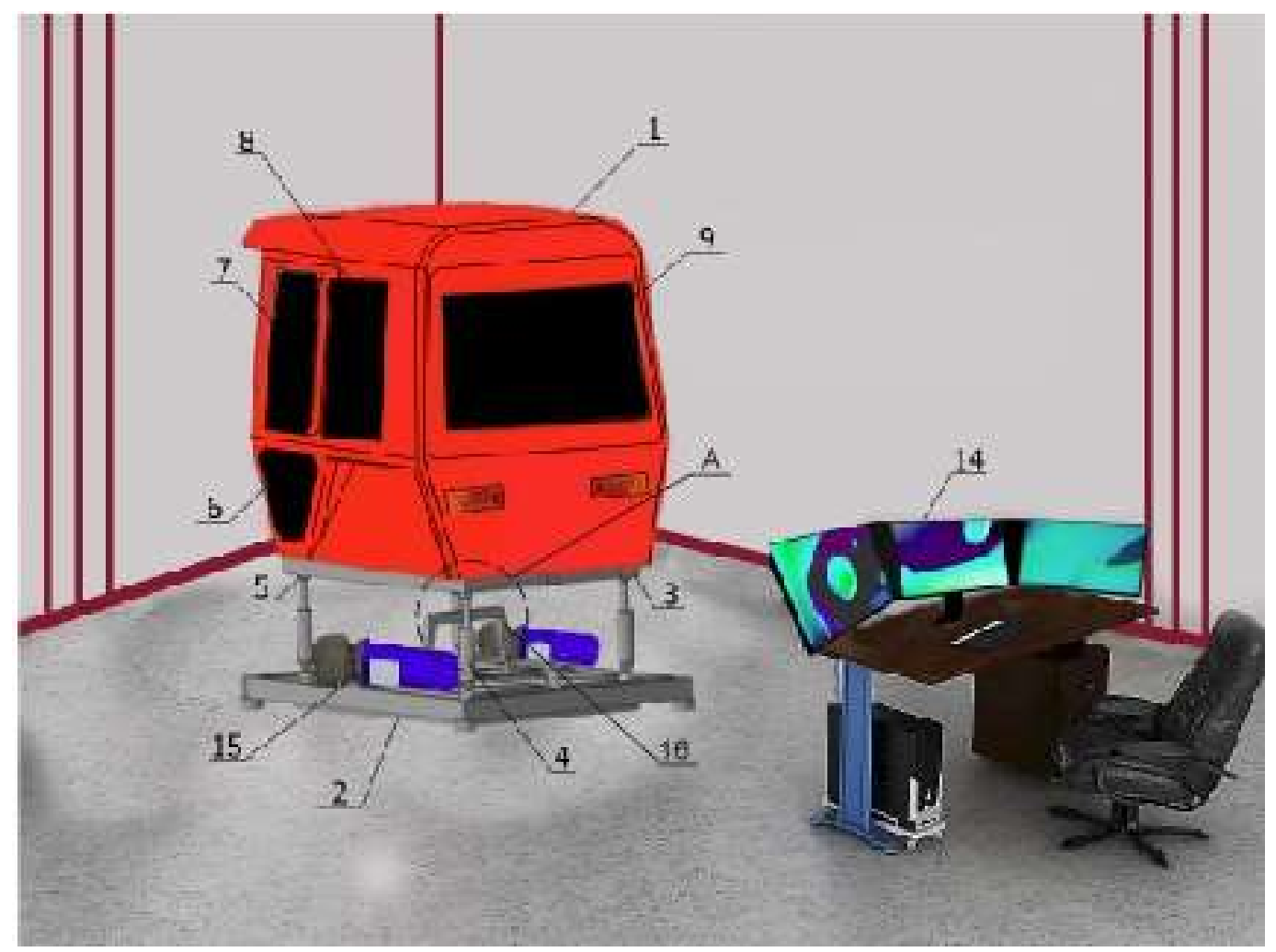

Fig. 1: Tractor and Agricultural Equipment Simulation System

Monitors located around the perimeter of the tractor cabin display the learner the environment and show everything around the vehicle up to $360^{\circ}$.

The proposed design works as follows: the vertical movement of the movable base 3 is ensured by the synchronous movement of four pneumatic cylinders 4 from the compressed air supply system 15 . The stationary 2 and movable 3 bases are a rigid frame, pneumatic cylinders 4 of reciprocating motion and suspension elements at the point of their connection with the movable and fixed bases are equipped with spatial hinges 5 . With the synchronous movement of the pneumatic cylinders 4 , the specified displacement values in the vertical plane are provided. In this case, the central hinge 18 provides additional stability to the platform.

The training simulator allows the trainee $[7,8,9]$ :

- To practice basic motor skills of wheel tractor driving;

- To study the general principles of wheel tractor control in different weather conditions and time of day;

- To study and acquire skills of operating a wheeled tractor, including with various trailed and hinged units, in practice without the risk and depreciation costs associated with the operation of a real training vehicle, maintenance costs and fuel and lubricants;

- To carry out automatic recording of students' mistakes and save the statistical results of training and examination races in a personalized database.

The software of the 3D tractor movement simulator, considering the physical parameters and dynamics of the vehicle, as well as the properties of the virtual environment, provides training and examination runs on an agricultural field.

The simulation system allows the trainee $[6,8,9]$ :

- To study the composition, location of controls and instrumentation of the cabin, as well as practical training in the rules for using controls;

- To study the order of pre-starting and starting the engine, warming it up after starting, stopping the engine, monitoring its operation;

- To simulate starting-off techniques from different positions, gear shifting, taxiing, braking in various ways, reverse motion;

- To simulate acceleration characteristics, changes in the speed of movement in the speed range of a real vehicle, the time of inertia, the time of rolling on ascents and descents;

- To study the control of the hydraulic system and attachments;

- To study the operation peculiarities of rear PTO driven machines;

- To simulate different times of the day: day/night; 
- To simulate a sound signal, the noise of a running engine, and the main units and components of the machine at the trainee's place;

- To simulate the occurrence of simple malfunctions, reflected in the change in instrument readings and/or noise effects;

- To use an intelligent system for selecting the optimal mode of the machine-tractor unit [10].

One of the advantages of the proposed design of a training simulator for controlling motor and tractor equipment and agricultural units is the availability of a VR simulator for mastering the necessary skills when performing maintenance in a virtual space.

Fig. 2 shows a student immersed in virtual reality for a shift maintenance, consisting of an instructor workstation 1, base stations 2, VIVE controllers 3, HTC VIVE helmet 4, wireless adapter and communication module 5, and QC 3.0. fast charge battery 6.

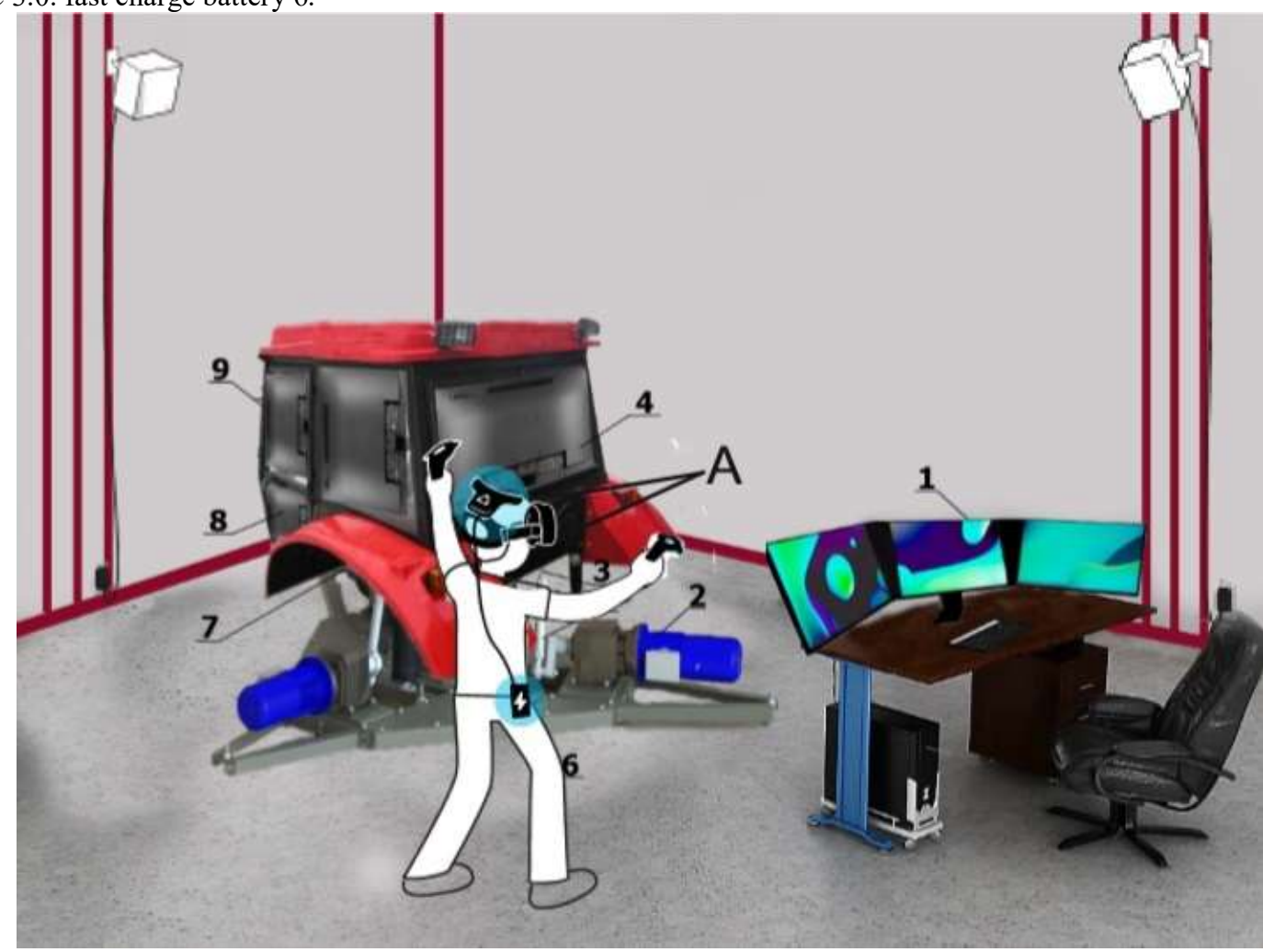

Fig. 2: VR Simulator

The simulator operates as follows. A computer generates a virtual space. At the installation site of the simulator, a border is formed by means of base stations, beyond which the user should not go. The generated virtual space is displayed on the helmet screen and duplicated on the instructor's computer with continuous conversion according to the programmed program.

\section{Result \& Discussion}

This simulator offers to simulate a virtual shift maintenance service for the Belarus-1523 tractor. With the help of software and hardware, the student will be able to move around to complete tasks. VIVE wireless trackers are used for additional immersion and tracking of the necessary tools for shift maintenance, and their number may change in the process. The VIVE tracker transfers any object of the real world to the virtual space. The user in the virtual world will be able to freely approach the equipment and perform the necessary tasks, which will also be monitored and controlled by the instructor at the working computer. This simulator is educational in nature. It offers several modes of maintenance, including independent work, actions with pop-up windows of prompts, etc. In addition, the results of the trainee's work can be recorded for its detailed analysis, clarification of the correct and consistent algorithm of actions.

Thus, the developed simulator will make it possible to increase the efficiency of the training process for tractor drivers in vocational training centers and other educational institutions with the acquisition of skills in driving tractor equipment, including using agricultural hinged and trailed units, as well as their technical maintenance. 


\section{Conclusion}

The principles of developing practical skills are being laid down with simultaneous theoretical training in modern simulators and in training and educational programs based on them. A special place in the development and implementation of virtual reality systems is occupied by the process of perception of a virtual space and the interaction of their operators with objects located in this space. The development of modern computer technologies makes it possible to significantly improve the quality of training operators to control various equipment including automotive vehicles. The developed simulator will make it possible to increase the efficiency of the training process for tractor drivers in vocational training centres and other educational institutions with the acquisition of skills in driving tractor equipment, particularly, using agricultural mounted and trailed machines, as well as carrying out their maintenance.

\section{References}

1. Manufacturer's educational equipment, techniques, and visual aids (http://gkuo.ru/index.php). 2. Drozdov V.B., Zelenin A.N. The use of simulators with multimedia technologies in the study of agricultural machines // AVU. 2011. No. 12-1.

3. Rybalkin D.A. Analysis of information models of simulators for training tractor drivers to control tractor equipment and agricultural units // Innovations in environmental management and protection in emergency situations. Proceedings of the VII International Scientific and Practical Conference. 2020. P. 382-387.

4. Zotova M.N., Stoiakova K.L. Analysis of the training methodology for transport workers using training simulators // Simvol Nauki. 2019. No. 11.

5. Serikova M.G., Terekhov V.M. Improvement of the training of road transport specialists // Transport business of Russia. 2014. No. 3. P. 68-69.

6. Kniazeva G.V. Virtual reality and professional visualization technologies // Bulletin of Volzhsky University. V.N. Tatishchev. 2010. No. 15, P. 68-76.

7. Roganov V.R. Features of 3D-imaging optical-hardware-software systems // Theory and practice of simulation and creation of simulators. 2015. P. 83-91.

8. Chetvergova M.V., Roganov V.R., Semochkin A.V. Using optical-hardware-software systems for teaching control of moving objects // Modern problems of science and education. 2014. No. 6. P. 174.

9. Koloskov B.B. Application of a six-step dynamic platform in a driving simulator for armored vehicles // Bulletin of Tula State University. Technical science. 2017. No. 11 (3). P. 246-252.

10. RF patent No. 123521 08.06.2012. The measurement system for choosing the optimal composition of the machine-tractor unit and modes of its operation / Kotsar Iu.A., Pluzhnikov S.V., Golovashchenko G.A., Kumakov Iu.A., Leonov S.V. 